\title{
Effects of exogenous glucagon-like peptide-1 on blood pressure, heart rate, gastric emptying, mesenteric blood flow and glycaemic responses to oral glucose in older individuals with normal glucose tolerance or type 2 diabetes
}

\author{
Laurence G. Trahair $^{1,2}$ • Michael Horowitz ${ }^{1,2}$ - Julie E. Stevens ${ }^{3}$ • \\ Christine Feinle-Bisset ${ }^{1,2} \cdot$ Scott Standfield ${ }^{1,2} \cdot$ Diana Piscitelli ${ }^{1,4}$. \\ Christopher K. Rayner ${ }^{1,2}$ • Adam M. Deane ${ }^{5,6} \cdot$ Karen L. Jones $^{1,2}$
}

Received: 11 February 2015 / Accepted: 30 April 2015 /Published online: 6 June 2015

(C) Springer-Verlag Berlin Heidelberg 2015

\begin{abstract}
Aims/hypothesis A postprandial fall in BP occurs frequently in older individuals and in patients with type 2 diabetes. The magnitude of this decrease in BP is related to the rate of gastric emptying (GE). Intravenous administration of glucagon-like peptide-1 (GLP-1) attenuates the hypotensive response to intraduodenal glucose in healthy older individuals. We sought to determine the effects of exogenous GLP-1 on BP, GE, superior mesenteric artery (SMA) flow and glycaemic response to oral ingestion of glucose in healthy older individuals and patients with type 2 diabetes.

Methods Fourteen older volunteers (six men, eight women; age $72.1 \pm 1.1$ years) and ten patients with type 2 diabetes (six men, four women; age $68.7 \pm 3.4$ years; $\mathrm{HbA}_{1 \mathrm{c}} 6.6 \pm 0.2 \%$ [48.5 \pm $2.0 \mathrm{mmol} / \mathrm{mol}$; ; nine with blood glucose managed with metformin, two with a sulfonylurea and one with a dipeptidyl-peptidase 4 inhibitor) received an i.v. infusion of GLP-1 $\left(0.9 \mathrm{pmol} \mathrm{kg}^{-1} \mathrm{~min}^{-1}\right)$
\end{abstract}

Karen L. Jones

karen.jones@adelaide.edu.au

1 Discipline of Medicine, The University of Adelaide, Royal Adelaide Hospital, North Terrace, Adelaide, SA 5000, Australia

2 NHMRC Centre of Research Excellence in Translating Nutritional Science to Good Health, The University of Adelaide, Adelaide, SA, Australia

3 School of Pharmacy and Medical Sciences, University of South Australia, Adelaide, SA, Australia

4 School of Health Sciences, University of South Australia, Adelaide, SA, Australia

5 Intensive Care Unit, Emergency Services Building, Royal Adelaide Hospital, Adelaide, SA, Australia

6 Discipline of Acute Care Medicine, The University of Adelaide, Adelaide, SA, Australia or saline $(154 \mathrm{mmol} / 1 \mathrm{NaCl})$ for $150 \mathrm{~min}(t=-30 \mathrm{~min}$ to $t=$ $120 \mathrm{~min}$ ) in randomised order. At $t=0 \mathrm{~min}$, volunteers consumed a radiolabelled $75 \mathrm{~g}$ glucose drink. BP was assessed with an automated device, GE by scintigraphy and SMA flow by ultrasonography. Blood glucose and serum insulin were measured. Results GLP-1 attenuated the fall in diastolic BP after the glucose drink in older individuals $(p<0.05)$ and attenuated the fall in systolic and diastolic BP in patients with type 2 diabetes $(p<0.05)$. GE was faster in patients with type 2 diabetes than in healthy individuals $(p<0.05)$. In both groups, individuals had slower GE $(p<0.001)$, decreased SMA flow $(p<0.05)$ and a lower degree of glycaemia $(p<0.001)$ when receiving GLP-1. Conclusions/interpretation Intravenous GLP-1 attenuates the hypotensive response to orally administered glucose and decreases SMA flow, probably by slowing GE. GLP-1 and 'short-acting' GLP-1 agonists may be useful in the management of postprandial hypotension.

Keywords Blood pressure · Gastric emptying · Glucagon-like peptide-1 - Glucose

$\begin{array}{ll}\text { Abbreviations } \\ \text { GE } & \text { Gastric emptying } \\ \text { GLP-1 } & \text { Glucagon-like peptide-1 } \\ \text { GLP-1R } & \text { Glucagon-like peptide-1 receptor } \\ \text { HR } & \text { Heart rate } \\ \text { PPH } & \text { Postprandial hypotension } \\ \text { SMA } & \text { Superior mesenteric artery }\end{array}$

\section{Introduction}

There is considerable interest in the cardiovascular effects of glucagon-like peptide-1 (GLP-1) and its agonists [1-3]. Phase 
3 studies focusing on the blood-glucose-lowering effects of GLP-1 agonists indicate durable, modest reductions in systolic and, less consistently, diastolic blood pressure (BP), and a slight rise in heart rate (HR) [4-7]. Postprandial hypotension (PPH), defined as a fall in systolic $\mathrm{BP} \geq 20 \mathrm{mmHg}$ within $2 \mathrm{~h}$ of a meal [8], is a common disorder, associated with substantial morbidity and increased mortality [9], for which current management is suboptimal [10]. Groups most affected are older individuals, particularly those in residential care, and patients with autonomic dysfunction, including those with diabetes [10].

In healthy older individuals and patients with type 2 diabetes, the postprandial fall in BP and increase in superior mesenteric artery (SMA) blood flow are greater when the rate of gastric emptying (GE), or intraduodenal glucose infusion, is relatively faster [11, 12], while gastric distension attenuates the fall in BP [13]. GE in healthy individuals exhibits a wide interindividual variation of $\sim 4-17 \mathrm{~kJ} / \mathrm{min}(\sim 1-4 \mathrm{kcal} / \mathrm{min})$ [14]; this is increased in diabetes because of the high prevalence of delayed [15], and occasionally rapid, GE [16]. The reduction in postprandial glucose following acute administration of GLP-1 [17-19] or 'short-acting' GLP-1 agonists [20, 21] relates primarily to slowing of GE but clinical studies relating to the effects of GLP-1 and its agonists on BP have not discriminated between effects on fasting vs postprandial BP.

We recently reported that exogenous GLP-1 attenuates the hypotensive response to intraduodenal infusion of glucose at $13 \mathrm{~kJ} / \mathrm{min}$ (3 kcal/min) [22]. GLP-1 has a pressor effect when the 'protective' effects of gastric distension are bypassed, supporting the concept that it may have efficacy in the management of PPH.

We hypothesised that i.v. infusion of GLP-1 would slow the GE of orally administered glucose in healthy older individuals and patients with type 2 diabetes and that this effect would be associated with attenuation of the fall in BP and increases in SMA flow and glycaemia.

\section{Methods}

\section{Participants}

Fourteen healthy older individuals (six men, eight women, age $72.1 \pm 1.1$ years, BMI $26.0 \pm 0.7 \mathrm{~kg} / \mathrm{m}^{2}$ ) and ten patients with type 2 diabetes (six men, four women, age $68.7 \pm 3.4$ years, BMI $28.0 \pm 1.2 \mathrm{~kg} / \mathrm{m}^{2}$, duration of known diabetes $9.4 \pm$ 1.8 years and $\mathrm{HbA}_{1 \mathrm{c}} 6.6 \pm 0.2 \%$ [ $\left.48.5 \pm 2.0 \mathrm{mmol} / \mathrm{mol}\right]$ ) were recruited via a database or advertisement. Nine of the patients with type 2 diabetes were taking oral hypoglycaemic medication (nine taking metformin, two a sulfonylurea and one sitagliptin); none was using insulin. Antihypertensive medication was being taken by four of the healthy individuals (all angiotensin-converting enzyme [ACE] inhibitors) and five patients with type 2 diabetes (four ACE inhibitors and one calcium-channel blocker). None of the patients with type 2 diabetes had microvascular complications and all had normal plasma creatinine. Individuals with previous gastrointestinal disease or surgery, significant respiratory or cardiac disease or alcohol abuse were excluded. All medication was withheld for $24 \mathrm{~h}$ before each study day.

\section{Protocol}

Participants were studied on two occasions, separated by at least 1 week when they attended the Department of Nuclear Medicine, Positron Emission Tomography and Bone Densitometry at the Royal Adelaide Hospital at 08:30 hours after an overnight fast. On arrival, the participant was seated in front of a gamma camera and one i.v. cannula was inserted into the left antecubital vein for blood sampling and another into the right antecubital vein for infusion of GLP-1. A cuff was placed around the upper left arm to measure BP and HR. Commencing at $t=-30 \mathrm{~min}$, each participant received, in randomised, double-blind fashion, an i.v. infusion of GLP-1 (Bachem, Bubendorf, Switzerland) at a rate of $0.9 \mathrm{pmol} \mathrm{kg}^{-1} \mathrm{~min}^{-1}$ or control $(0.9 \% \mathrm{wt} / \mathrm{vol}$. saline, $154 \mathrm{mmol} / \mathrm{l} \mathrm{NaCl})$ for $150 \mathrm{~min}$ (i.e. from $t=-30 \mathrm{~min}$ to $t=120 \mathrm{~min}$ ) [22]. At $t=-3 \mathrm{~min}$, they consumed a drink comprising $75 \mathrm{~g}$ glucose and $5 \mathrm{~g}$ 3-O-methyl-D-glucopyranose (Carbosynth, Compton, UK) dissolved in water (volume $300 \mathrm{ml}$ ), labelled with $20 \mathrm{MBq}\left[{ }^{99 \mathrm{~m}} \mathrm{Tc}\right.$ ] calcium phytate (Radpharm Scientific, Belconnen, ACT, Australia) within $3 \mathrm{~min}$. At $t=120 \mathrm{~min}$, the i.v. cannulae were removed. On one of the two days, autonomic function was then evaluated using standardised cardiovascular reflex tests [23].

The protocol was approved by the Human Research Ethics Committee of the Royal Adelaide Hospital, and each volunteer provided written, informed consent. All experiments were carried out in accordance with the Declaration of Helsinki.

\section{BP and HR}

BP and HR were measured using an automated BP monitor (DINAMAP ProCare 100; GE Medical Systems, Milwaukee, WI, USA), every $3 \mathrm{~min}$ for $15 \mathrm{~min}$ prior to the i.v. infusion $(t=-45$ to $-30 \mathrm{~min}$ ) and every $3 \mathrm{~min}$ between $t=-30$ and 120 min. Pre-i.v. 'baseline' BP and HR were calculated as an average of the measurements made at $t=-39,-36$ and -33 min. Pre-drink 'baseline' BP and HR was the measurement made at $t=-3 \mathrm{~min}$. PPH was defined as a fall in systolic $\mathrm{BP} \geq 20 \mathrm{mmHg}$ that was sustained for at least $20 \mathrm{~min}$.

\section{GE}

Radioisotopic data were acquired for 120 min following the drink ( $60 \mathrm{~s}$ frames between $t=0 \mathrm{~min}$ and $t=60 \mathrm{~min}$, then $180 \mathrm{~s}$ 
frames between $t=60 \mathrm{~min}$ and $t=120 \mathrm{~min}$ ). Data were corrected for movement, radionuclide decay and $\gamma$-ray attenuation [24]. The amount of the drink remaining in the stomach at $15 \mathrm{~min}$ intervals between $t=0 \mathrm{~min}$ and $t=120 \mathrm{~min}$ and, where possible, the 50\% GE time (T50) were calculated [24].

\section{SMA blood flow}

SMA flow was measured using a Logiq e ultrasound system (GE Healthcare Technologies, Sydney, NSW, Australia) and a 3.5C broad spectrum 2.5-4.0 MHz convex linear array transducer. Measurements were made prior to the commencement of the i.v. infusion and consumption of the drink (i.e. at $t=-33 \mathrm{~min}$ and $t=-3 \mathrm{~min}$, respectively) and every $15 \mathrm{~min}$ between $t=0 \mathrm{~min}$ and $t=120 \mathrm{~min}$. Blood flow $(\mathrm{ml} / \mathrm{min})$ was calculated as: $\pi \times r^{2} \times \mathrm{TAMV} \times 60$, where $r$ is the radius of the SMA and TAMV is the time-averaged mean velocity [25]. Two measurements were made at each time point by the same investigator (LGT).

\section{Blood glucose and serum insulin}

Venous blood was collected at $t=-33 \mathrm{~min}$ and $t=-3 \mathrm{~min}$, every $15 \mathrm{~min}$ from $t=0$ to $t=60 \mathrm{~min}$ and at $t=90 \mathrm{~min}$ and $t=120 \mathrm{~min}$. Blood glucose $(\mathrm{mmol} / \mathrm{l})$ was determined, using a glucometer (Medisense Companion 2 meter; Medisense, Waltham, MA, USA). Serum insulin was measured by ELISA (10-1113; Mercodia, Uppsala, Sweden); the sensitivity was $6.0 \mathrm{pmol} / 1$ and the coefficient of variation was $2.6 \%$ within, and $7.6 \%$ between, assays [26].

\section{Cardiovascular autonomic nerve function}

Autonomic nerve function was assessed using cardiovascular reflex tests [23]. Parasympathetic function was evaluated by the variation ( $\mathrm{R}-\mathrm{R}$ interval) of the HR during deep breathing and the response to standing ('30:15' ratio) and sympathetic function by the fall in systolic BP in response to standing. Each result was scored as $0=$ normal, $1=$ borderline and $2=$ abnormal for a total maximum score of 6 [23]. A score $\geq 3$ was considered to indicate autonomic dysfunction [23].

\section{Statistical analysis}

$\mathrm{BP}$ and HR were assessed as changes from the pre-i.v. or predrink baselines, whereas GE, SMA flow, blood glucose and serum insulin were analysed as absolute values. AUCs between $t=-30 \mathrm{~min}$ and $t=0 \mathrm{~min}$ and between $t=0 \mathrm{~min}$ and $t=60 \mathrm{~min}$ were calculated using the trapezoidal rule. Changes in each variable over time (from $t=-30$ to $0 \mathrm{~min}$ and from $t=0-60 \mathrm{~min}$ ) were evaluated with repeated-measures ANOVA. Differences between treatments and groups (i.e. treatment $\times$ group interaction) were evaluated with repeated- measures ANOVA. Baseline measurements and AUCs within groups were compared using Student's paired $t$ test. The number of participants was based on a power calculation, derived from our study in which GLP-1 in identical dosage was administered to healthy older individuals [22], so that there was $80 \%$ power to detect an $8 \mathrm{mmHg}$ difference in the AUC for systolic BP between the study days. A $p$ value $<0.05$ was considered significant.

\section{Results}

The studies were all well tolerated. There was no difference in age $(p=0.36)$, BMI $(p=0.17)$ or the score for autonomic neuropathy $(p=0.61)$ when comparing the healthy individuals with the patients with type 2 diabetes. None of the participants had autonomic neuropathy. In three healthy individuals and three diabetic patients, SMA measurements were not feasible due to intra-abdominal gas.

\section{BP and HR}

Healthy individuals Between $t=-30 \mathrm{~min}$ and $t=0 \mathrm{~min}$ there was no change in systolic BP on either study day (Table 1). Following the glucose drink there was a rise, followed by a sustained fall, in systolic BP ( $p<0.001$ for both infusions), with no difference between the study days (treatment, $p=$ 0.47 , time, $p<0.001$; treatment $\times$ time, $p=0.12$ ), although at $t=\sim 15-60$ min mean systolic BP was lower on the control day (Fig. 1a).

Between $t=-30 \mathrm{~min}$ and $t=0 \mathrm{~min}$ there was no change in diastolic BP on either study day (Table 1). Following the glucose drink there was a fall in diastolic BP $(p<0.001$ for both infusions), which was greater during the control infusion (treatment, $p<0.001$; time, $p<0.001$; treatment $\times$ time, $p<0.001)$. The AUC for diastolic BP was smaller during the control than during the GLP-1 infusion $(p<0.001)$ (Fig. 1b).

Between $t=-30 \mathrm{~min}$ and $t=0 \mathrm{~min}$ there was no change in HR on either study day (Table 1). Following the glucose drink there was no significant change in HR on either study day, although mean values were higher during the control than during the GLP-1 infusion (Fig. 1c).

Patients with type 2 diabetes Between $t=-30 \mathrm{~min}$ and $t=0$ min there was no change in systolic BP on either study day (Table 1). Following the glucose drink there was a rise on both study days, followed by a sustained fall in systolic BP during the control infusion $(p<0.05)$ but not during the GLP-1 infusion $(p=0.32)$. Systolic BP was lower in patients receiving the control infusion (treatment, $p=0.06$; time, $p=0.22$; treatment $\times$ time, $p<0.05$ ) and the AUC for the control infusion tended to be smaller ( $p=0.06)$ (Fig. 1b). 
Table 1 Baseline variables before i.v. infusion of GLP-1 or saline (control) and consumption of a glucose drink in healthy older individuals and patients with type 2 diabetes

\begin{tabular}{|c|c|c|c|c|}
\hline \multirow[t]{2}{*}{ Variable } & \multicolumn{2}{|c|}{ Healthy individuals $(n=14)$} & \multicolumn{2}{|c|}{ Patients with type 2 diabetes $(n=10)$} \\
\hline & Pre-i.v. infusion & Pre-drink & Pre-i.v. infusion & Pre-drink \\
\hline \multicolumn{5}{|c|}{ Systolic BP (mmHg) } \\
\hline Control & $119.0 \pm 4.5$ & $118.5 \pm 5.1$ & $125.0 \pm 7.0$ & $126.7 \pm 8.0$ \\
\hline GLP-1 & $122.6 \pm 5.2$ & $124.0 \pm 4.5$ & $120.1 \pm 5.1$ & $122.0 \pm 5.2$ \\
\hline \multicolumn{5}{|c|}{ Diastolic BP (mmHg) } \\
\hline Control & $65.1 \pm 2.5$ & $65.3 \pm 2.4$ & $69.0 \pm 2.8$ & $68.3 \pm 3.3$ \\
\hline GLP-1 & $66.6 \pm 3.2$ & $64.8 \pm 2.9$ & $66.6 \pm 2.1$ & $65.9 \pm 2.7$ \\
\hline \multicolumn{5}{|c|}{ HR (beats/min) } \\
\hline Control & $60.9 \pm 2.4$ & $61.3 \pm 2.4$ & $66.8 \pm 3.3$ & $67.9 \pm 3.2$ \\
\hline GLP-1 & $60.6 \pm 2.5$ & $59.9 \pm 2.6$ & $66.5 \pm 3.1$ & $67.0 \pm 3.1$ \\
\hline \multicolumn{5}{|c|}{ SMA flow $(\mathrm{ml} / \mathrm{min})^{\mathrm{a}}$} \\
\hline Control & $542 \pm 34$ & $504 \pm 39$ & $587 \pm 91$ & $654 \pm 113$ \\
\hline GLP-1 & $551 \pm 54$ & $534 \pm 63$ & $741 \pm 139$ & $771 \pm 119$ \\
\hline \multicolumn{5}{|c|}{ Blood glucose (mmol/1) } \\
\hline Control & $5.6 \pm 0.1$ & $5.6 \pm 0.2$ & $8.4 \pm 0.3$ & $8.3 \pm 0.3$ \\
\hline GLP-1 & $5.8 \pm 0.1$ & $5.5 \pm 0.1$ & $8.6 \pm 0.4$ & $8.3 \pm 0.4$ \\
\hline \multicolumn{5}{|c|}{ Insulin (pmol/1) } \\
\hline Control & $32.6 \pm 3.0$ & $30.6 \pm 3.7$ & $51.2 \pm 3.7$ & $50.0 \pm 5.4$ \\
\hline GLP-1 & $31.0 \pm 3.2$ & $37.7 \pm 3.7$ & $57.5 \pm 8.0$ & $53.1 \pm 16.8$ \\
\hline
\end{tabular}

Data are means \pm SEM

Participants received an i.v. infusion of GLP-1 $\left(0.9\right.$ pmol kg$\left.{ }^{-1} \mathrm{~min}^{-1}\right)$ or saline (control) from $t=-30$ min to $t=120$ min on one of two days in random order. Pre-i.v. infusion measurements were made at $t=-33 \mathrm{~min}$; pre-drink measurements were made at $t=-3 \mathrm{~min}$, before consumption of a $75 \mathrm{~g}$ glucose drink at $t=0 \mathrm{~min}$

${ }^{a}$ For SMA flow measurements, $n=11$ and 7, respectively, for healthy individuals and patients with type 2 diabetes

Between $t=-30 \mathrm{~min}$ and $t=0$ min there was no change in diastolic BP on either study day (Table 1). Following the drink there was no change in diastolic BP on either study day, but diastolic BP was lower in those receiving the control infusion than in those receiving GLP-1 (treatment, $p=0.14$; time, $p=$ 0.13; treatment $\times$ time, $p<0.05)$ (Fig. 1d).

Between $t=-30 \mathrm{~min}$ and $t=0 \mathrm{~min}$ there was no change in HR (Table 1). Following the drink there was no change in HR on either study day $(p=0.18)$. HR increased during GLP-1 infusion $(p<0.01)$, although there was no difference between the study days (treatment, $p=0.21$; time, $p=0.94$; treatment $\times$ time, $p=0.45)($ Fig. $1 \mathrm{e})$.

Comparison between the groups There was no difference between the two groups in the AUC $t=0-60 \mathrm{~min}$ for systolic $\mathrm{BP}$, diastolic BP or HR for either study day.

\section{GE}

Healthy individuals The T50 on the control study day was $121.7 \pm 11.7 \mathrm{~min}$. GE was slowed by GLP-1 (e.g. retention at $t=120$ min: control, $47.7 \pm 4.6 \%$; GLP-1, 71.4 $44.8 \%$, $p<0.001$ ) (Fig. 2a).

Patients with type 2 diabetes The T50 on the control study day was $87.7 \pm 10.4$ min. GE was slowed by GLP-1 (e.g. retention at $t=120 \mathrm{~min}$ : control, $32.1 \pm 5.3 \%$; GLP-1, 63.5 $7.9 \%, p<0.005$ ) (Fig. 2b).

Comparison between the groups The T50 on the control study day was shorter $(p<0.05)$ and the percentage of drink retained in the stomach at $t=120 \mathrm{~min}$ was lower $(p<0.05)$ in the patients with type 2 diabetes than in the healthy individuals. There was no difference between the groups in the retention at $t=120 \mathrm{~min}$ for the GLP-1 study day $(p=0.40)$.

\section{SMA blood flow}

Healthy individuals Between $t=-30 \mathrm{~min}$ and $t=-3 \mathrm{~min}$ there was a trend for SMA flow to be lower on the control study day $(p=0.06)$, without any change during GLP-1 $(p=$ 0.50) (Table 1). Following the glucose drink there was an 
Fig. 1 Effects of i.v. infusion of GLP-1 (0.9 pmol kg ${ }^{-1} \mathrm{~min}^{-1}$, white symbols) or saline (control, black symbols) on systolic BP $(\mathbf{a}, \mathbf{b})$, diastolic BP $(\mathbf{c}, \mathbf{d})$ and $\mathrm{HR}$ (e, f) before and after $75 \mathrm{~g}$ oral glucose in healthy older individuals $(n=14 ; \mathbf{a}, \mathbf{c}, \mathbf{e})$ and patients with type 2 diabetes $(n=10 ; \mathbf{b}, \mathbf{d}, \mathbf{f})$. Systolic BP: type 2 diabetes patients, $p<0.05$. Diastolic BP: healthy older individuals, $p<0.001$; type 2 diabetes patients, $p<0.05$; $p$ values are for GLP-1 vs control ANOVA $t=0-60 \mathrm{~min}$
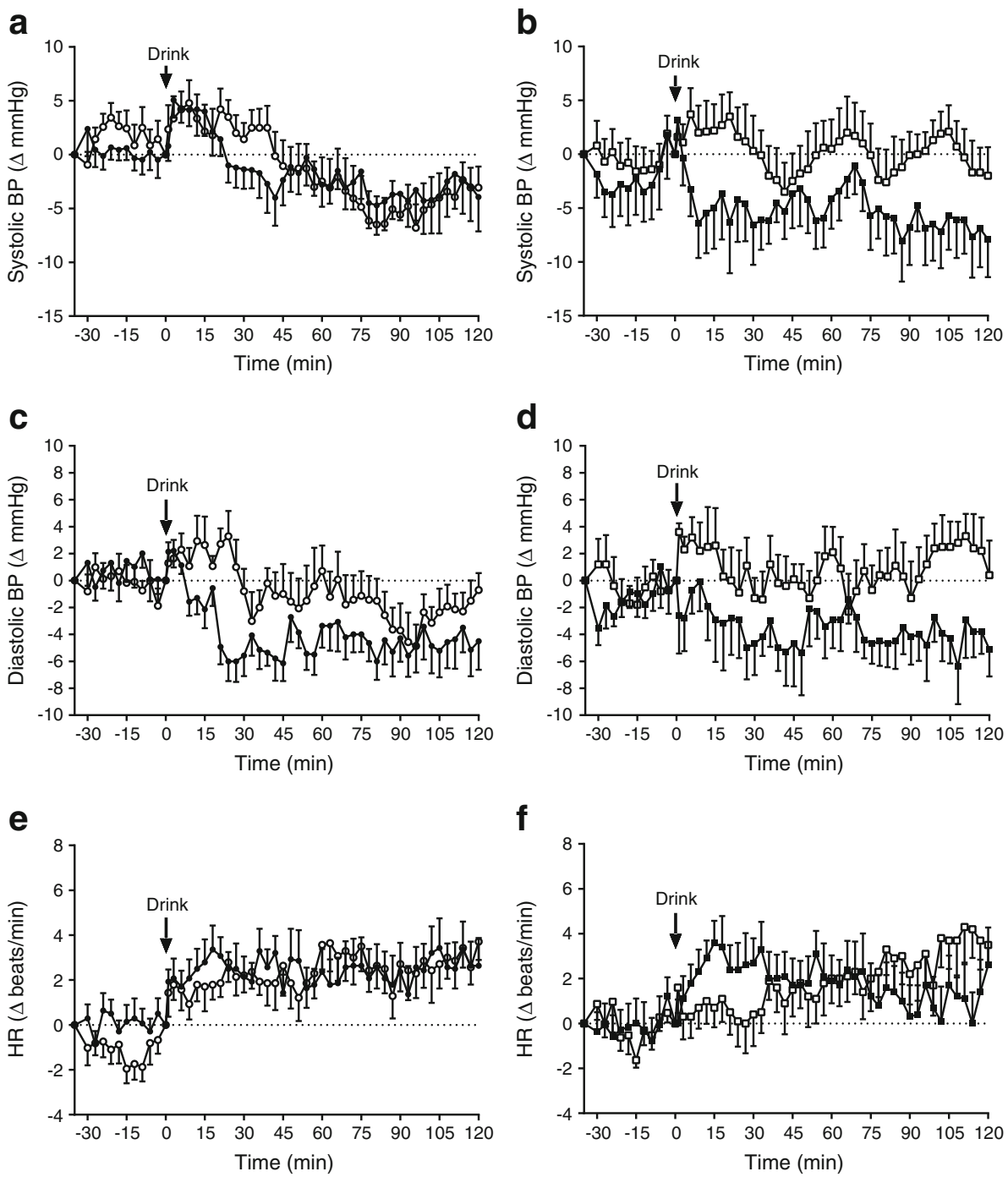

increase in SMA flow ( $p<0.001$ for both infusions); this increase was less during GLP-1 infusion (treatment, $p<0.001$; time, $p<0.001$; treatment $\times$ time, $p<0.01)$. The AUC for SMA blood flow was smaller during the GLP-1 than the control infusion $(p<0.001)$ (Fig. 3a).

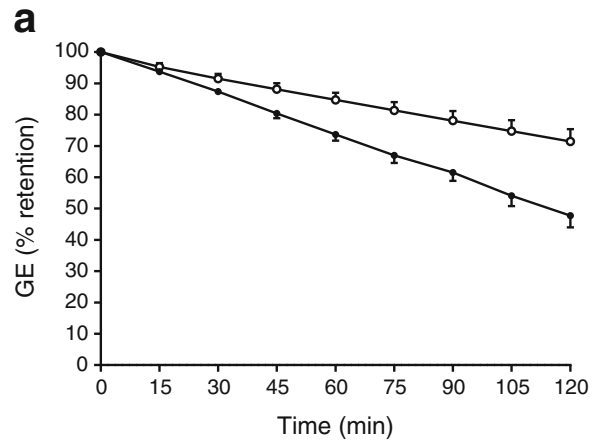

Fig. 2 Effects of i.v. infusion of GLP-1 $\left(0.9 \mathrm{pmol} \mathrm{kg}^{-1} \mathrm{~min}^{-1}\right.$, white symbols) or saline (control, black symbols) on GE of a $75 \mathrm{~g}$ oral glucose load in healthy older individuals $(n=14 ;$ a) and patients with type 2
Patients with type 2 diabetes At the pre-drink baseline measurement, SMA flow was slightly less on the control study day than on the GLP-1 study day $(p<0.05)$ (Table 1$)$. Between $t=$ $-30 \mathrm{~min}$ and $t=-3 \mathrm{~min}$ there was no change in SMA flow on either study day. Following the glucose drink, there was an

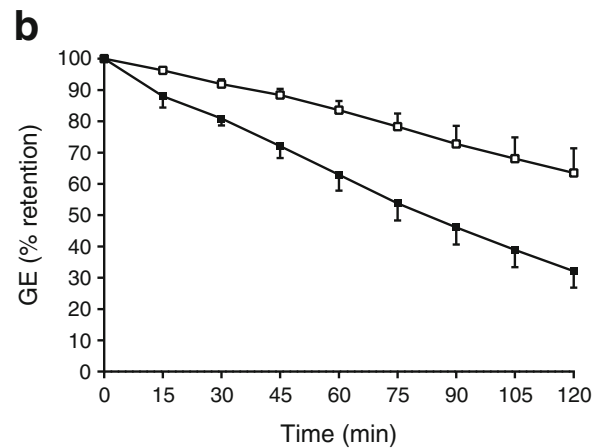

diabetes $(n=10$; b). Gastric retention at $t=120 \mathrm{~min}$, GLP-1 vs control: healthy older individuals, $p<0.001$; type 2 diabetes patients, $p<0.005$ 


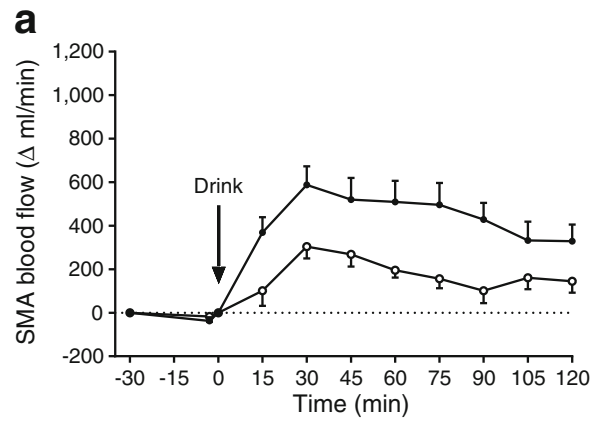

Fig. 3 Effects of i.v. infusion of GLP-1 (0.9 pmol kg-1 $\mathrm{min}^{-1}$, white symbols) or saline (control, black symbols) on the SMA blood flow response to oral administration of $75 \mathrm{~g}$ glucose in healthy older

increase in SMA flow during the control infusion $(p<0.05)$ and no change during the GLP-1 infusion $(p=0.16)$. While there was no difference between the study days (treatment, $p=0.07$; time, $p<0.01$; treatment $\times$ time, $p=0.18$ ), the AUC for SMA flow was smaller during the GLP-1 than the control infusion $(p<0.05)$ (Fig. 3b).

Comparison between the groups There were no differences between the healthy individuals and the patients with type 2 diabetes in SMA blood flow at either the pre-i.v. or pre-drink baseline (Table 1) and there was no difference in the AUC 0-60 min for either study day.

\section{Blood glucose and serum insulin}

Healthy individuals Blood glucose at pre-i.v. baseline was slightly less on the control day than on the GLP-1 day b

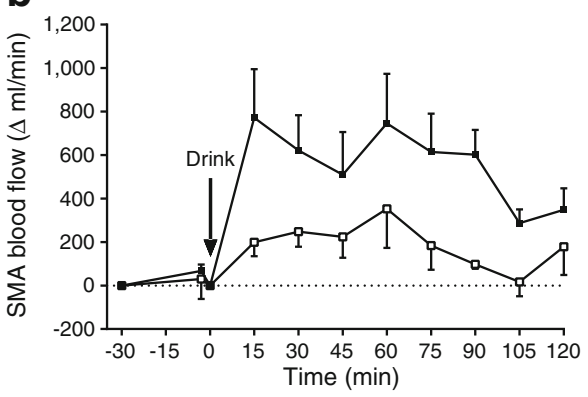

individuals $(n=11 ; \mathbf{a})$ and patients with type 2 diabetes $(n=7 ; \mathbf{b})$. AUC $t=0-60 \mathrm{~min}, \mathrm{GLP}-1$ vs control: healthy older individuals, $p<0.001$; type 2 diabetes patients, $p<0.05$

$(p<0.05)$ (Table 1). Between $t=-30 \mathrm{~min}$ and $t=-3 \mathrm{~min}$, there was a modest decrease in blood glucose during the GLP-1 infusion $(p<0.05)$ but no change during the control infusion $(p=$ 0.40 ). Following the glucose drink, there was an increase in blood glucose on both study days ( $p<0.001$ for both) which was less during GLP-1 infusion (treatment, $p<0.001$; time, $p<0.001$; treatment $\times$ time, $p<0.001)$. The AUC for blood glucose was smaller during the GLP-1 than the control infusion $(p<0.001)$ (Fig. 4a).

At the pre-drink baseline serum insulin was higher on the GLP-1 study day $(p<0.01)$ (Table 1). Between $t=-30 \mathrm{~min}$ and $t=-3$ min there was an increase in insulin during the GLP-1 infusion $(p<0.005)$ but no change during the control infusion $(p=0.26)$. Following the glucose drink there were comparable increases $(p<0.001$ for both) in serum insulin on both study days (treatment, $p<0.05$; time, $p<0.001$; treatment $\times$ time, $p=$ 0.37 ), although the AUC for serum insulin was smaller during the GLP-1 than the control infusion $(p<0.05)$ (Fig. 4c).
Fig. 4 Effects of i.v. infusion of GLP-1 (0.9 pmol kg ${ }^{-1} \mathrm{~min}^{-1}$, white symbols) or saline (control, black symbols) on blood glucose $(\mathbf{a}, \mathbf{b})$ and serum insulin $(\mathbf{c}, \mathbf{d})$ before and after $75 \mathrm{~g}$ oral glucose in healthy older individuals $(n=14 ; \mathbf{a}, \mathbf{c})$ and patients with type 2 diabetes $(n=10 ; \mathbf{b}, \mathbf{d})$. GLP-1 vs control ANOVA $t=0-60 \mathrm{~min}$ : for blood glucose in healthy older individuals, $p<0.001$; for blood glucose in type 2 diabetes patients, $p<0.001$; for serum insulin in type 2 diabetes patients, $p<0.05$ a

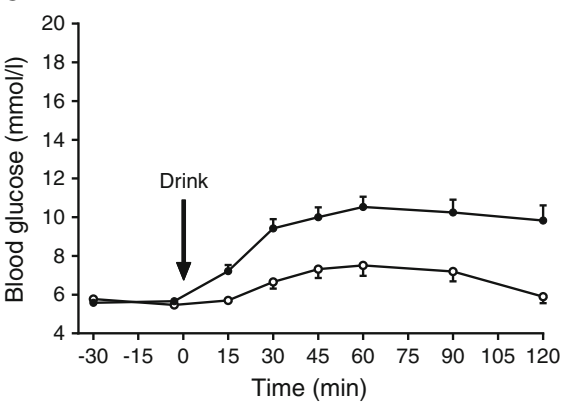

C

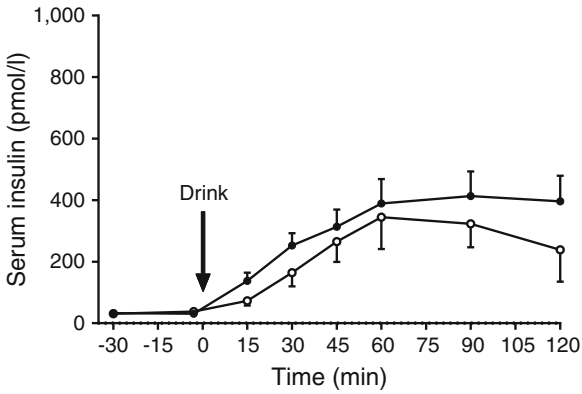

b

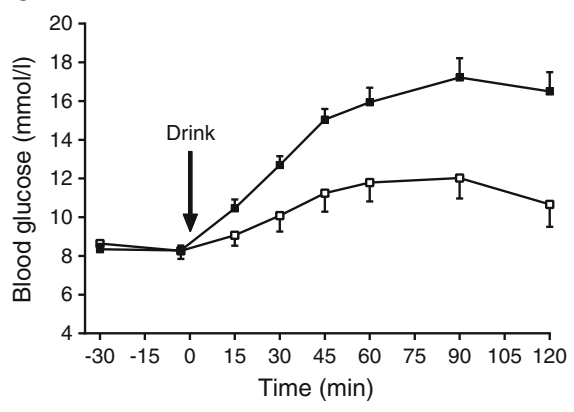

d

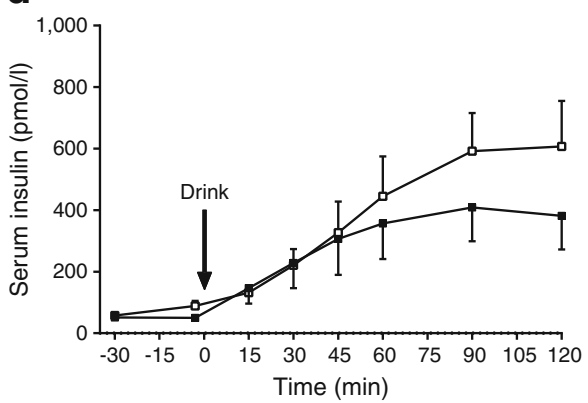


Patients with type 2 diabetes Between $t=-30 \mathrm{~min}$ and $t=-3 \mathrm{~min}$ there was a slight decrease in blood glucose during the GLP-1 infusion $(p<0.05)$ but no change during the control infusion $(p=0.48)$ (Table 1). Following the glucose drink, there was an increase in blood glucose $(p<0.001$ for both infusions) which was less during the GLP-1 infusion (treatment, $p<0.005$; time, $p<0.001$; treatment $\times$ time, $p<0.001)$. The AUC for blood glucose was smaller during the GLP-1 than the control infusion $(p<0.005)$ (Fig. 4b).

At the pre-drink baseline serum insulin was higher on the GLP-1 study day $(p<0.05)$ (Table 1$)$. Between $t=-30 \mathrm{~min}$ and $t=-3$ min there was an increase in serum insulin during the GLP-1 infusion $(p<0.05)$ but no change during the control infusion $(p=0.71)$. Following the glucose drink, there was an increase in serum insulin on both study days $(p<0.001$ for both). Serum insulin levels were higher during the GLP1 infusion (treatment, $p=0.38$; time, $p<0.001$; treatment $\times$ time, $p<0.05)$, although there was no difference in AUC $(p=0.68)$ between the two infusions (Fig. $4 d$ ).

Comparison between the groups Pre-i.v. and pre-drink baseline blood glucose levels ( $p<0.001$ for both study days) (Table 1) and the blood glucose AUC 0-60 min were greater in patients with type 2 diabetes than in healthy individuals ( $p<0.001$ for both infusions).

Pre-i.v. and pre-drink baseline serum insulin levels were greater in patients with type 2 diabetes than in healthy individuals ( $p<0.005$ for both study days) (Table 1 ) but there was no difference in the AUC 0-60 min for either study day.

\section{Relationships between the variables}

In patients with type 2 diabetes the difference in AUC for blood glucose was inversely related to the difference in intragastric retention at $t=120 \mathrm{~min}$ between the control and GLP-1 infusions $(R=-0.65, p<0.05)$ indicating that the slower the GE the greater the reduction in glycaemia. There were no significant relationships between changes in BP or SMA flow and GE.

\section{Discussion}

This study establishes that acute, i.v., administration of GLP-1 (0.9 $\left.\mathrm{pmol} \mathrm{kg}^{-1} \mathrm{~min}^{-1}\right)$ to healthy older individuals and patients with type 2 diabetes attenuates the fall in BP and rise in SMA flow induced by orally administered glucose and confirms that GLP-1 slows GE and diminishes glycaemia. The effect on BP is consistent with our hypothesis and supports the concept that GLP-1 and GLP-1 agonists may prove effective in the management of $\mathrm{PPH}$.

GLP-1 and GLP-1 receptor (GLP-1R) agonists induce a sustained elevation of BP in rodents [2, 3, 27], attributable to central and peripheral mechanisms, but not in largeranimal models [28] or apparently humans [29, 30]. However, in a recent study, a modest $(\sim 5 \mathrm{mmHg})$ increase in systolic (but not diastolic) BP, associated with an increase in cardiac output attributable to rises in stroke volume as well as HR, was evident in healthy middle-aged men in response to an i.v. infusion of GLP-1 (1.5 pmol kg-1 $\left.\mathrm{min}^{-1}\right)$ [31]. It was suggested that the increase in cardiac output may be a compensatory response to vasodilatation elsewhere. The effectiveness of GLP-1R agonists in reducing BP in clinical trials of type 2 diabetes and obesity is most evident in individuals with higher baseline BP $[1,5,6]$ and may be attributable to reductions in tubular sodium reabsorption [32] or central sympathetic output [33] as well as peripheral vasodilatory effects [34]. In contrast to findings in rodents [35], GLP-1 and GLP-1R agonists do not appear to promote the secretion of atrial natriuretic peptide in humans [30, 31]. In our study GLP-1 had no effect on $\mathrm{BP}$ or HR in the $30 \mathrm{~min}$ preceding ingestion of the glucose drink, which reduced BP in both healthy older individuals and patients with type 2 diabetes. GLP-1 attenuated the glucosedrink-induced fall in diastolic, but not systolic, BP in healthy older individuals. In type 2 diabetes patients both systolic and diastolic BP post-glucose drink were greater following GLP-1 than control infusion. The magnitude of the effect of GLP-1 on BP was substantial ( $\sim 10 \mathrm{mmHg}$ difference) and may relate to the slowing of GE, but other mechanisms are likely to be important, particularly as GLP-1 reduces the hypotensive response to intraduodenal glucose [22]. In healthy older individuals, orally [36] and intraduodenally administered [37] guar reduces the hypotensive response to glucose administered via the same routes, and the $\alpha$-glucosidase inhibitor acarbose has comparable effects on the response to orally [24] and intraduodenally administered [38] sucrose. These observations suggest that the slowing of nutrient absorption from the small intestine is a critical factor. In view of recent observations made using a higher dose of GLP-1 [31], a direct pressor effect of GLP-1 represents an alterative explanation and it would be interesting to evaluate the effect of GLP-1 infusion without an oral glucose load.

Cross-sectional studies have reported there to be a $30-50 \%$ prevalence of gastroparesis in longstanding type 1 or 2 diabetes [15, 39], although GE may be accelerated [16], perhaps particularly in 'early' type 2 diabetes [39]. Our patients had type 2 diabetes of relatively short duration, good glycaemic control and no microvascular complications. The observed acceleration in GE may be an underestimate given that acute hyperglycaemia slows GE [40]. The acute slowing of GE by exogenous GLP-1 is substantial [17-19], as we confirmed, so that the consequent reduction in glucose may be associated with a reduction, rather than an increase, in insulin [17-19]. While blood glucose levels were lower during the GLP-1 infusion than the control infusion, the overall glycaemic profile was predictably greater in patients with type 2 diabetes. That 
GLP-1 had a mild insulinotropic effect prior to the glucose drink is consistent with previous observations [22]. In healthy individuals, blood glucose exceeded the threshold for an insulinotropic effect of GLP-1 [34] only during the control day, whereas in patients with type 2 diabetes levels were above this threshold during both study days. This may account for why serum insulin was higher following GLP-1, compared with control, in patients with type 2 diabetes, whereas in healthy individuals, the opposite was observed. In healthy individuals, the reduction in blood glucose caused by GLP-1 was greater than we observed in response to an intraduodenal infusion of glucose at $13 \mathrm{~kJ} / \mathrm{min}$ ( $3 \mathrm{kcal} / \mathrm{min}$ ) [22], which is likely to reflect the slowing of GE. Glucose lowering per se also represents a potential confounder in interpreting the effects of GLP-1 on BP. Ideally, we would have included a positive control for the antihyperglycaemic effect of GLP-1.

The glucose-stimulated increase in SMA flow was reduced in both healthy individuals and patients with type 2 diabetes when GLP-1 was administered. This effect is probably related to the slowing of GE rather than a direct effect of GLP-1, particularly as GLP-1 in identical dosage potentiated the increase in SMA flow induced by intraduodenal glucose [22].

In interpreting these results other potential limitations should be recognised. While most volunteers were normotensive some were taking antihypertensive medication, although the medication was withdrawn for a minimum of $24 \mathrm{~h}$. As the postprandial fall in BP is greater when the preprandial BP is higher [10], it is likely that the effects of GLP-1 will be greater in patients with hypertension. Although blood glucose was quantified with a glucometer, the observed changes appeared consistent between individual participants. All the patients with type 2 diabetes had relatively well-controlled, uncomplicated diabetes and studies of the effects of GLP-1 on postprandial BP in diabetes associated with autonomic neuropathy are warranted, given that the response to GLP-1 may be influenced by autonomic function [41]. There is also potential for a discordance between the effects of i.v. and s.c. administration of GLP-1 on BP, as appears to be the case for glucose lowering in patients with type 2 diabetes and, possibly, the induction of upper gastrointestinal symptoms [42].

Despite its importance, information relating to the dietary and pharmacological management of PPH is limited [10]. The current study should be regarded as 'proof of principle' as we did not study patients with PPH. However, in the elderly, PPH probably represents a continuum (i.e. in healthy older individuals there is predictably a postprandial fall in BP, which is not the case in healthy young [11]). Given our observations, evaluation of the effect of GLP-1 agonists on BP in PPH is indicated. It will be important to determine whether the acute effects that we observed are maintained with chronic administration. We assessed the acute responses to GLP-1, and it is now recognised that the slowing of GE by exogenous GLP-1 is subject to tachyphylaxis with sustained exposure [43, 44].
Intuitively, once- or twice-daily administration of 'short-acting' preparations of GLP-1 agonists, such as exenatide and lixisenatide, which predominantly diminish postprandial glucose by slowing GE $[45,46]$, may have greater efficacy than once-weekly administration of longer-acting drugs, such as liraglutide and modified-release exenatide, where the slowing of GE appears to be modest with chronic use $[45,46]$.

In summary, in healthy older individuals and patients with type 2 diabetes, acute i.v. administration of GLP-1, in a dose of $0.9 \mathrm{pmol} \mathrm{kg}^{-1} \mathrm{~min}^{-1}$, attenuates the hypotensive response to orally administered glucose. This effect is associated with slowing of GE and reduction in SMA blood flow and glycaemia. These observations suggest the following: (1) GLP-1 agonists may be effective in the management of PPH and (2) studies relating to the effects of GLP-1 and its agonists on BP should discriminate between the fasted and postprandial state.

Acknowledgements The authors would like to acknowledge the Pharmacy Department, Royal Adelaide Hospital for randomisation and preparation of the study drug, the Department of Nuclear Medicine, Positron Emission Tomography and Bone Densitometry for their support in providing resources and R. Tippett (Discipline of Medicine, The University of Adelaide, Australia) and C. Tran (School of Pharmacy and Medical Sciences, University of South Australia, Australia) for technical assistance on the study days.

Funding This study was supported by the National Health and Medical Research Council (NHMRC) of Australia (grant 627189). LGT is supported by an Australian Postgraduate Award and a Dawes scholarship from the Royal Adelaide Hospital. KLJ's salary is funded by an NHMRC Senior Career Development Award (grant 627011) and CFB's salary is funded by an NHMRC Senior Research Fellowship (grant 627002).

Duality of interest $\mathrm{MH}$ has participated in Advisory Boards and/or symposia for Novo Nordisk, Sanofi, Novartis, Eli Lilly, Merck Sharp \& Dohme, Boehringer Ingelheim and AstraZeneca and has received honoraria for this activity. CKR has received research funding from Merck, Eli Lilly and Novartis. All other authors declare that there is no duality of interest associated with their contribution to this manuscript.

Contribution statement LGT, MH, CFB, DP, CKR, AMD and KLJ were involved in the conception and design of the study. LGT was responsible for coordination, participant recruitment, data collection and interpretation and statistical analysis. MH and KLJ carried out data interpretation and statistical analysis. JES collected and interpreted data. AMD interpreted the data. LGT, MH, JES, CFB, CKR, DP and KLJ were involved in drafting the manuscript. SS collected and analysed data. KLJ had overall responsibility for the study. All authors critically reviewed the manuscript and approved the publication of this final version of the manuscript.

\section{References}

1. Seufert J, Gallwitz B (2014) The extra-pancreatic effects of GLP-1 receptor agonists: a focus on the cardiovascular, gastrointestinal and central nervous systems. Diabetes Obes Metab 16:673-688 
2. Ussher JR, Drucker DJ (2012) Cardiovascular biology of the incretin system. Endocr Rev 33:187-215

3. Ussher JR, Drucker DJ (2014) Cardiovascular actions of incretinbased therapies. Circ Res 114:1788-1803

4. Davies MJ, Kela R, Khunti K (2011) Liraglutide - overview of the preclinical and clinical data and its role in the treatment of type 2 diabetes. Diabetes Obes Metab 13:207-220

5. Fonseca VA, Devries JH, Henry RR, Donsmark M, Thomsen HF, Plutzky J (2014) Reductions in systolic blood pressure with liraglutide in patients with type 2 diabetes: insights from a patient-level pooled analysis of six randomized clinical trials. J Diabetes Complicat 28:399-405

6. Klonoff DC, Buse JB, Nielsen LL et al (2008) Exenatide effects on diabetes, obesity, cardiovascular risk factors and hepatic biomarkers in patients with type 2 diabetes treated for at least 3 years. Curr Med Res Opin 24:275-286

7. Stonehouse A, Walsh B, Cuddihy R (2011) Exenatide once-weekly clinical development: safety and efficacy across a range of background therapies. Diabetes Technol Ther 13:1063-1069

8. Jansen RW, Lipsitz LA (1995) Postprandial hypotension: epidemiology, pathophysiology, and clinical management. Ann Intern Med 122:286-295

9. Fisher AA, Davis MW, Srikusalanukul W, Budge MM (2005) Postprandial hypotension predicts all-cause mortality in older, low-level care residents. J Am Geriatr Soc 53:1313-1320

10. Trahair LG, Horowitz M, Jones KL (2014) Postprandial hypotension: a systematic review. J Am Med Dir Assoc 15:394-409

11. Jones KL, Tonkin A, Horowitz M et al (1998) Rate of gastric emptying is a determinant of postprandial hypotension in non-insulindependent diabetes mellitus. Clin Sci (Lond) 94:65-70

12. Vanis L, Gentilcore D, Rayner CK et al (2011) Effects of small intestinal glucose load on blood pressure, splanchnic blood flow, glycaemia and GLP-1 release in healthy older subjects. Am J Physiol Regul Integr Comp Physiol 300:R1524-R1531

13. Vanis L, Gentilcore D, Hausken T et al (2010) Effects of gastric distension on blood pressure and superior mesenteric artery blood flow responses to intraduodenal glucose in healthy older subjects. Am J Physiol Regul Integr Comp Physiol 299:R960-R967

14. Collins PJ, Horowitz M, Cook DJ, Harding PE, Shearman DJ (1983) Gastric emptying in normal subjects - a reproducible technique using a single scintillation camera and computer system. Gut 24:1117-1125

15. Chang J, Rayner CK, Jones KL, Horowitz M (2011) Diabetic gastroparesis - backwards and forwards. J Gastroenterol Hepatol 26(Suppl 1):46-57

16. Phillips WT, Schwartz JG, McMahan CA (1992) Rapid gastric emptying of an oral glucose solution in type 2 diabetic patients. $\mathrm{J}$ Nucl Med 33:1496-1500

17. Nauck MA, Niedereichholz U, Ettler R et al (1997) Glucagon-like peptide 1 inhibition of gastric emptying outweighs its insulinotropic effects in healthy humans. Am J Physiol 273:E981-E988

18. Willms B, Werner J, Holst JJ, Orskov C, Creutzfeldt W, Nauck MA (1996) Gastric emptying, glucose responses, and insulin secretion after a liquid test meal: effects of exogenous glucagon-like peptide1 (GLP-1)-(7-36) amide in type 2 (noninsulin-dependent) diabetic patients. J Clin Endocrinol Metab 81:327-332

19. Little TJ, Pilichiewicz AN, Russo A et al (2006) Effects of intravenous glucagon-like peptide-1 on gastric emptying and intragastric distribution in healthy subjects: relationships with postprandial glycemic and insulinemic responses. J Clin Endocrinol Metab 91:1916-1923

20. Horowitz M, Flint A, Jones KL et al (2012) Effect of the once-daily human GLP-1 analogue liraglutide on appetite, energy intake, energy expenditure and gastric emptying in type 2 diabetes. Diabetes Res Clin Pract 97:258-266
21. Jelsing J, Vrang N, Hansen G, Raun K, Tang-Christensen M, Knudsen LB (2012) Liraglutide: short-lived effect on gastric emptying-long lasting effects on body weight. Diabetes Obes Metab 14:531-538

22. Trahair LG, Horowitz M, Hausken T, Feinle-Bisset C, Rayner CK, Jones KL (2014) Effects of exogenous glucagon-like peptide-1 on the blood pressure, heart rate, mesenteric blood flow, and glycemic responses to intraduodenal glucose in healthy older subjects. J Clin Endocrinol Metab 99:E2628-E2634

23. Piha SJ (1991) Cardiovascular autonomic reflex tests: normal responses and age-related reference values. Clin Physiol 11:277-290

24. Gentilcore D, Bryant B, Wishart JM, Morris HA, Horowitz M, Jones KL (2005) Acarbose attenuates the hypotensive response to sucrose and slows gastric emptying in the elderly. Am J Med 118: 1289.e5-e11

25. Perko MJ (2001) Duplex ultrasound for assessment of superior mesenteric artery blood flow. Eur J Vasc Endovasc Surg 21:106-117

26. Trahair LG, Horowitz M, Rayner CK et al (2012) Comparative effects of variations in duodenal glucose load on glycemic, insulinemic, and incretin responses in healthy young and older subjects. J Clin Endocrinol Metab 97:844-851

27. Gardiner SM, March JE, Kemp PA, Bennett T, Baker DJ (2010) Possible involvement of GLP-1(9-36) in the regional haemodynamic effects of GLP-1(7-36) in conscious rats. Br J Pharmacol 161:92-102

28. Edwards CM, Edwards AV, Bloom SR (1997) Cardiovascular and pancreatic endocrine responses to glucagon-like peptide-1(7-36) amide in the conscious calf. Exp Physiol 82:709-716

29. Mendis B, Simpson E, MacDonald I, Mansell P (2012) Investigation of the haemodynamic effects of exenatide in healthy male subjects. Br J Clin Pharmacol 74:437-444

30. Skov J, Holst JJ, Gotze JP, Frokiaer J, Christiansen JS (2014) Glucagon-like peptide-1: effect on pro-atrial natriuretic peptide in healthy males. Endocr Connect 3:11-16

31. Asmar A, Simonsen L, Asmar M et al (2015) Renal extraction and acute effects of glucagon-like peptide- 1 on central and renal hemodynamics in healthy men. Am J Physiol Endocrinol Metab 208: E641-E649

32. Gutzwiller JP, Tschopp S, Bock A et al (2004) Glucagon-like peptide 1 induces natriuresis in healthy subjects and in insulin-resistant obese men. J Clin Endocrinol Metab 89:3055-3061

33. Yamamoto H, Lee CE, Marcus JN et al (2002) Glucagon-like peptide-1 receptor stimulation increases blood pressure and heart rate and activates autonomic regulatory neurons. J Clin Invest 110:43-52

34. Ban K, Noyan-Ashraf MH, Hoefer J, Bolz SS, Drucker DJ, Husain M (2008) Cardioprotective and vasodilatory actions of glucagonlike peptide 1 receptor are mediated through both glucagon-like peptide 1 receptor-dependent and -independent pathways. Circulation 117:2340-2350

35. Kim M, Platt MJ, Shibasaki T et al (2013) GLP-1 receptor activation and Epac2 link atrial natriuretic peptide secretion to control of blood pressure. Nat Med 19:567-575

36. Jones KL, MacIntosh C, Su YC et al (2001) Guar gum reduces postprandial hypotension in older people. J Am Geriatr Soc 49:162-167

37. O'Donovan D, Feinle-Bisset C, Chong C et al (2005) Intraduodenal guar attenuates the fall in blood pressure induced by glucose in healthy older adults. J Gerontol A Biol Sci Med Sci 60:940-946

38. Gentilcore D, Vanis L, Wishart JM, Rayner CK, Horowitz M, Jones KL (2011) The alpha ( $\alpha$ )-glucosidase inhibitor, acarbose, attenuates the blood pressure and splanchnic blood flow responses to intraduodenal sucrose in older adults. J Gerontol A Biol Sci Med Sci 66:917-924 
39. Phillips LK, Rayner CK, Jones KL, Horowitz M (2014) Measurement of gastric emptying in diabetes. J Diabetes Complicat 28:894-903

40. Fraser RJ, Horowitz M, Maddox AF, Harding PE, Chatterton BE, Dent J (1990) Hyperglycaemia slows gastric emptying in type 1 (insulin-dependent) diabetes mellitus. Diabetologia 33:675-680

41. Delgado-Aros S, Vella A, Camilleri M et al (2003) Effects of glucagon-like peptide-1 and feeding on gastric volumes in diabetes mellitus with cardio-vagal dysfunction. Neurogastroenterol Motil 15:435-443

42. Nauck MA, Baranov O, Ritzel RA, Meier JJ (2013) Do current incretin mimetics exploit the full therapeutic potential inherent in GLP-1 receptor stimulation? Diabetologia 56:1878-1883
43. Nauck MA, Kemmeries G, Holst JJ, Meier JJ (2011) Rapid tachyphylaxis of the glucagon-like peptide 1-induced deceleration of gastric emptying in humans. Diabetes 60:1561-1565

44. Umapathysivam MM, Lee MY, Jones KL et al (2014) Comparative effects of prolonged and intermittent stimulation of the glucagonlike peptide 1 receptor on gastric emptying and glycemia. Diabetes 63:785-790

45. Horowitz M, Rayner CK, Jones KL (2013) Mechanisms and clinical efficacy of lixisenatide for the management of type 2 diabetes. Adv Ther 30:81-101

46. Phillips LK, Deane AM, Jones KL, Rayner CK, Horowitz M (2015) Gastric emptying and glycaemia in health and diabetes mellitus. Nat Rev Endocrinol 11:112-128 